\title{
Relações de poder em uma rede do terceiro setor: um estudo de caso*
}

\author{
Áureo Magno Gaspar Pinto** \\ Luciano Antonio Prates Junqueira***
}

Sumário: 1. Introdução; 2. Redes sociais e relações de poder; 3 . Rede Cooperativa de Promoção da Cidadania (Cooperapic); 4. Considerações finais.

Summary: 1 Introduction; 2. Social networks and power relationships; 3. Cooperative Network for the Promotion of Citizenship (Cooperapic); 4. Final remarks.

Palavras-chavE: relações de poder; redes sociais; terceiro setor; descentralização.

KEY WORDs: power relationship; social networks; third sector; decentralization.

Este artigo apresenta um estudo de caso em que são analisadas as relações de poder em uma estrutura de rede de organizações sem fins lucrativos, Cooperapic, para avaliar se concentração de poder no núcleo gestor da rede poderia ser um fator de manutenção da integridade estrutural. Foi utilizada a análise de redes sociais para que fossem elaborados cenários de relacionamento entre os atores e mensurada a concentração de poder na rede. Os resultados da pesquisa permitiram identificar que a rede se constitui de forma descentralizada, com baixo índice de poder central e com subgrupos que concentram o poder, o que pode favorecer sua fragmentação. Foi verificada a importância do núcleo gestor na coesão da rede, bem como os impactos que sua exclusão poderia ocasionar.

\footnotetext{
* Artigo recebido em fev. e aceito em jul. 2009.

** Mestre em administração pela Pontifícia Universidade Católica de São Paulo (PUC-São Paulo); graduado em administração de empresas pela Escola de Administração de Empresas de São Paulo da Fundação Getulio Vargas (Eaesp/FGV). Endereço: Rua Tuiuti, 436, ap. 114 — Tatuapé - CEP 05014-901, São Paulo, SP, Brasil. E-mail: aureo.gaspar@gmail.com.

*** Professor titular da Faculdade de Economia, Administração, Contabilidade e Atuárias da Pontifícia Universidade Católica de São Paulo (FEA/PUC-São Paulo); coordenador do Núcleo de Estudos Avançados do Terceiro Setor (Neats/PUC-São Paulo); professor assistente doutor da Universidade Católica de Santos. Endereço: Rua Monte Alegre, 984, 4º andar — Perdizes - CEP 05014-901, São Paulo, SP. E-mail: junq@pucsp.br.
} 


\begin{abstract}
Power relationships in a third sector network: a case study
This article presents a case study analyzing power relationships in a reticular structure of non-profit organizations, Cooperapic, so as to evaluate to what extent the power concentration and the nucleation at a central actor can be a relevant factors to the network's structural integrity. Social network analysis was used as to compare relationship scenarios and to measure the power concentration. The analysis revealed that the network is decentralized and has a low level of total power, but it has clusters which concentrate power and may fragment the network. The study also showed the importance of the central actor as well as the impacts of its exclusion from the network.
\end{abstract}

\title{
1. Introdução
}

As relações entre sujeitos por meio da comunicação, do conhecimento compartilhado, intensificam a troca e a reciprocidade entre indivíduos e entre organizações, tendo em vista a construção de redes para a superação dos problemas sociais. Essas redes sociais, formatadas a partir de objetivos definidos coletivamente, integram e articulam atores sociais para o desenvolvimento de estratégias de sustentabilidade. A existência de uma rede depende de uma realidade múltipla e complexa onde o reconhecimento do outro e a definição de objetivos comuns possibilitam a construção de um tecido social. Isso significa que a rede social se constitui a partir da interação entre os sujeitos.

Esse processo de relacionamento envolve negociação, mas também intermediação, trocas e concessões, pressupondo o exercício do poder. Há uma dinâmica das forças e influências que cada um dos participantes da rede exerce sobre aqueles com quem se relaciona, compartilhando valores e interesses.

A rede é uma metáfora, mas também uma realidade operativa, de construtos mentais, que permite o entendimento da realidade social e a superação dos problemas sociais que incidem sobre os diferentes atores sociais que a compõem. A ênfase no aspecto pragmático visualiza a rede como "um conjunto de participantes autônomos, unindo ideias e recursos em torno de valores e interesses compartilhados" (Marteleto, 2001:72). Compartilhar valores e interesses é também expandir o campo de visão do mundo e, portanto, um projeto de poder. A rede é uma estrutura social, mas também uma associação dotada de poder e mobilidade.

Relacionar-se para atingir objetivos comuns envolve interesses e poder, pois "em toda parte onde os homens agem em comum surge o poder" (Arendt, 2004:79). As relações de poder existentes no interior de uma rede promovem a maturidade relacional, envolvendo integração, colaboração e participação. 
As redes, tanto as informais quanto as formais, constroem-se a partir dessas relações sociais, o que implica conhecer a dinâmica pela qual cada participante influencia aqueles com quem se relaciona na realização de suas atividades.

Nessa perspectiva, redes informais podem se fortalecer, unindo pessoas em torno de um objetivo, para superar os problemas que afetam segmentos menos privilegiados da sociedade civil. As redes tendem a se formalizar, a se constituírem de forma operativa como organizações governamentais ou não governamentais. A formalização da rede impacta sua constituição interna, com o risco de aumentar a assimetria entre ganhos e benefícios auferidos por cada participante, mesmo que essas relações sejam democráticas e participativas.

Entender as relações de poder existentes no interior de uma rede do terceiro setor contribui para compreender a motivação e a gestão das pessoas em atividades não remuneradas, as implicações do trabalho voluntário, com foco no exercício do poder e na liderança (Fleury, Migueletto e Bloch, 2002; Junqueira, 2006). As forças e fragilidades relacionais de uma rede, os liames que unem seus atores e seus laços solidários podem ocasionar a estruturação de novas redes, ou mesmo o aprimoramento de outras já existentes e com atuação similar.

Este artigo investiga as relações de poder em uma rede de organizações do terceiro setor, para responder às seguintes questões: os laços entre os atores que constituem uma rede social condicionam o exercício de poder no seu interior? Quais os principais fatores que agregam esses atores e como a rede se mantém? Para responder a essas indagações será realizada a análise de redes sociais, identificando sua estrutura, seus atores e as relações de poder que estabelecem, medindo o grau de centralidade do poder e sua sustentabilidade para a existência da rede.

A seguir, são apresentados o poder e a horizontalidade das redes. Logo depois vem a metodologia da pesquisa e finalmente os resultados da pesquisa realizada na rede Cooperapic - Cooperativa de Promoção da Cidadania, existente na cidade de São Paulo.

\section{Redes sociais e relações de poder}

As redes sociais referem-se a um conjunto de indivíduos e organizações, conectados, que vão construindo e reconstruindo a estrutura social. Essa conexão se dá por meio das relações sociais que se manifestam de maneiras diversas e expressam a complexidade do mundo social. Vivemos em um mundo em movimento e as redes sociais desempenham um papel central para apreender tal 
realidade. A análise de redes sociais permite que sejam analisadas as relações entre indivíduos, grupos e organizações em uma dada sociedade.

O estudo de rede não é recente e vários são os saberes que têm contribuído para sua construção. É importante ressaltar a contribuição dos antropólogos, em especial os ligados à universidade de Manchester, que desenvolveram modelos matemáticos de redes para representar relações e atividades sociais como parentesco, amizade, relações políticas e de trabalho. Os estruturalistas de Harvard, na década de 1960, integraram diversas tradições buscando investigar, modelar e mensurar de forma matemática as estruturas e os papéis sociais (Martes et al., 2006).

A análise estrutural dos anos 1960 e 1970, inspirada na teoria dos sistemas e na análise de grafos, dividiu-se em duas grandes linhas: as redes completas e as redes pessoais. A análise das redes completas, ou integrais, tem como objeto a relação estrutural da rede com os grupos sociais. Trata da distribuição do poder na rede como um todo ou na relação desta com outros grupos. O estudo das redes pessoais tem como cerne a análise dos papéis representados pelos indivíduos nos diversos grupos sociais de que participa. Discute a composição dos laços sociais e conteúdo, direção e força desses laços que conectam pares de atores (Villasante, 2002).

A pesquisa sobre redes sociais, a partir de 1980, ganhou ênfase pela busca de modelos organizacionais flexíveis, que respondessem de forma adequada às mutações sociais (Nohria e Eccles, 1992). Privilegia a importância da relação entre atores e parte do pressuposto de que os relacionamentos são constitutivos da natureza humana e são elementos definidores da identidade dos atores sociais. Assim, a contribuição de Elias (1994:27) é relevante, pois para ele "cada pessoa parte de uma posição única em sua rede de relações e atravessa uma história singular até chegar à morte". As relações entre indivíduos e sociedade são algo singular, pois somente na relação com outros seres humanos se constrói a rede como totalidade dessa relação, pois as "redes estruturam a vida" (Marques, 2003:153).

Assim, há várias formas de se olhar a rede. Uma das perspectivas é a do comportamento humano, do mundo corporativo e das transações econômicas, em uma rede de relacionamentos interpessoais (Granovetter, 1973, 1985; Uzzi, 1996; Mizruchi, 1996). Granovetter (1973) introduz os conceitos de laços fortes e fracos, sendo as relações fracas as que ampliam os limites das redes ao conectar grupos que não possuíam ligações entre si. Já os laços fortes são os existentes com indivíduos conhecidos e que despendem mais tempo, intensidade emocional e trocas. Uma rede social, assim como um tecido, é uma malha de relacionamentos cujos vínculos possuem densidades diversas. 
Granovetter (1973), ao falar sobre vínculos, diferencia a função dos laços fortes e dos laços fracos para a eficácia das redes. Muitas vezes indivíduos fora dos padrões, que se movimentam entre comunidades diferentes, são os responsáveis por trazer ideias heterodoxas necessárias para que um grupo se adapte com sucesso às mudanças do ambiente. Ele também observou que os vínculos interpessoais fortes, como parentesco e amizade íntima, são menos importantes do que os vínculos fracos, como conhecimentos e afiliação a associações secundárias, para sustentar a coesão comunitária e a ação coletiva. Os vínculos fracos têm maior probabilidade de unir membros em pequenos grupos diferentes do que os vínculos fortes.

Já Burt (1992) privilegia a utilidade das conexões no interior de uma rede com acumulação de capital social, pois essas conexões podem prover poder ou valor, inclusive o econômico, aos seus integrantes. O capital social é um ativo que gera ganhos sociais e materiais, tanto para o indivíduo quanto para o grupo ao qual pertence. Quando em uma rede de relacionamentos há comprometimento das partes, é mais difícil cooperar quando não existe um contrato formal preestabelecido na relação. Essa visão encaminha para os estudos sobre a padronização estrutural da vida social.

Na padronização estrutural da vida social são identificados os atores que geram e criam laços em uma determinada rede, aumentando seu poder. As redes em geral designam movimentos institucionalizados com uma dinâmica voltada para a consolidação e o desenvolvimento das atividades dos indivíduos. As redes têm origem em movimentos que ocasionam sua criação e que determinam sua forma institucional (Marteleto e Silva, 2004). Cada indivíduo, ou organização, possui uma posição na rede que depende do capital social agregado. $O$ poder, no interior da rede social, é exercido em função da sua distribuição, mas também dessa posição dos atores, da estrutura das relações sociais, da interdependência desses diversos atores que a compõem. O poder deve ser examinado como algo que circula, que funciona em cadeia e se exerce em rede (Foucault, 1998).

Portanto, a análise de redes sociais permitirá verificar como a rede Cooperapic se estrutura e a dinâmica do poder no seu interior.

\section{Poder e horizontalidade nas redes organizacionais}

Os problemas ligados à horizontalidade das relações sociais entre os atores e o exercício do poder tornam-se mais evidentes quando a rede se formaliza juridicamente. A lei brasileira determina que a constituição de uma organiza- 
ção, na forma mais comum de uma associação, deve prever a eleição de um corpo diretivo e de conselheiros. O processo eletivo formal dá publicidade e legitimidade às pessoas eleitas para a representação do grupo, atribuindo-lhes poder. Os membros mais participativos e ativos, na rede, são fortes candidatos a participar do quadro diretivo eleito.

A manutenção do sistema dinâmico que é a rede pode concentrar poder em poucos atores, que atuem com mais empenho e detenham contatos ou conhecimentos, ou mesmo tenham maior disponibilidade para agregar-se em um núcleo gestor. Esse núcleo pode ser um fator de manutenção da rede, evitando o isolamento dos atores e reduzindo a possibilidade de fragmentação dos laços solidários. Pode também tornar-se um instrumento para promover a interdependência dos atores, para atingir os objetivos definidos coletivamente.

Assim, o papel da liderança, do núcleo gestor eleito, coordenando as ações da rede para atingir seus objetivos, possibilitará a transformação dos conhecimentos tácitos de cada ator em conhecimento explícito, sistematizando uma espiral de socialização (Nonaka e Takeuchi, 1995). Com isso, o núcleo gestor terá a missão de potencializar e catalisar o intercâmbio entre os diversos atores para dar continuidade ao grupo.

Essa não é a única possibilidade para orientar as ações da rede. Mas aquela pautada pelo consenso e não pela uniformidade, na perspectiva do associativismo voluntário, que está centrado na busca, pelo conjunto dos participantes, dos objetivos comuns, e não em uma ação preconizada por um ente diretor. Nesse sentido, não é o poder do ente central que dá força às ligações entre os diversos atores, mas a densidade das relações entre eles, abrindo espaço para novas lideranças.

Contudo, a existência de um núcleo gestor na rede muda essas relações, pois o poder, em princípio, está centrado no ente gestor, e essa centralidade do poder advém de sua capacidade de ofertar benefícios de interesse de cada associado. A inexistência do núcleo poderá ocasionar o enfraquecimento dos laços emocionais e colaborativos, fazendo com que o contato entre os membros da rede não seja suficiente para a manutenção da associação, dispersando esforços e causando o esfacelamento da rede. Nessa perspectiva será conduzido o entendimento do que ocorre com o poder na rede Cooperapic com um núcleo gestor, que deve ser um fator de aglutinação e mesmo de manutenção da mesma.

\section{Rede Cooperativa de Promoção da Cidadania (Cooperapic)}

Este artigo busca responder às questões sobre as relações de poder em uma malha de organizações formalmente conformada e articulada denominada 
Cooperapic - Cooperativa de Promoção da Cidadania. Essa rede foi escolhida por ser de fácil acesso às organizações que a compõem. A rede foi constituída em 1994, na Zona Sul da cidade de São Paulo, congregando organizações que têm como finalidade a promoção social e educacional de crianças e jovens. As entidades do terceiro setor, que compõem essa rede, foram formadas no final dos anos 1980 com o término do regime militar e a articulação do governo e da sociedade civil.

A Cooperapic é composta por um núcleo gestor, constituído por uma diretoria eleita pelos representantes das 56 organizações que formam a rede. Esses representantes gerenciam 248 unidades, que realizam cerca de $46 \mathrm{mil}$ atendimentos por mês. A rede com inserção social possui relações com governo, empresas e comunidade. Essas associações são de diversas origens: religiosas, de movimentos de bairro, de programas de atendimento público, entre outras. Essa diversidade faz com que as relações entre os membros da rede determinem a formação de subgrupos que condicionam suas práticas sociais. Como será visto no decorrer do artigo, hoje a rede é composta de organizações situadas em diversas regiões da cidade de São Paulo e mesmo na Grande São Paulo como é o caso do município de Embu.

\section{Metodologia da pesquisa}

A pesquisa, de natureza quantitativa, foi realizada com a utilização de um formulário elaborado para identificar as organizações que compõem a rede e as relações que estabelecem entre si e qual a intensidade. Foram realizadas 56 entrevistas por telefone com representantes das organizações. Além desses representantes, também foram entrevistados dois dirigentes do núcleo gestor.

As organizações componentes da rede Cooperapic foram identificadas por códigos, de A000 (o núcleo gestor) até A146, para se preservar a identidade dos respondentes e das organizações.

Os dados das entrevistas telefônicas foram inseridos em um programa especialista denominado ORA - organization risk analyser, escolhido por ter manuseio simples, ser gratuito (freeware), de origem acadêmica e com detalhada documentação e referência bibliográfica (Carley, 2003, 2004, 2008).

Os resultados foram interpretados de acordo com a metodologia de análise de redes sociais, que permite simular mudanças estruturais em um modelo computadorizado, sem intervenção na rede real, justificando sua escolha para a pesquisa. 
O mecanismo principal de exploração consistiu em comparar dois cenários, traçando-se as ligações atuais, simulando uma mudança de configuração e avaliando os impactos dessa alteração na distribuição de poder na rede.

Os dois cenários inseridos no ORA para simular a mudança de configuração foram denominados rede efetiva e rede sem núcleo. A rede efetiva é formada pelos atores que foram citados por outros atores como tendo vínculos (relações estáveis) com eles, durante o processo de pesquisa. Esses vínculos consistiam na participação em cursos, reuniões, projetos e elaboração de campanhas conjuntas.

Nesse modelo o núcleo gestor integra a rede em conjunto com as outras organizações que a compõem, é a chamada rede efetiva. Quando não se considera o núcleo gestor como participante da rede, ela é chamada rede sem núcleo. Nesse cenário o objetivo é identificar atores que devem ter presença mais significativa sem o núcleo gestor, para verificar em que medida a ausência do núcleo gestor contribui para a fragmentação da rede.

Definidos esses cenários, categorizaram-se os atores e foram selecionadas as medidas para compará-los. A Cooperapic foi analisada em função de sua estrutura e da conformação das relações de poder, resgatando-se a hipótese de que sua manutenção depende do núcleo gestor, comparando com o cenário de rede efetiva. Para traçar essas relações de poder, privilegiou-se o local de atuação, a participação em projetos alinhados à busca de subgrupos, bem como a análise dos grafos.

A rede foi tratada no software como um quadro flexível de matrizes, redes entrelaçadas que conectam entidades como pessoas, conhecimentos, recursos e tarefas. Ela fornece um meio de conceituar o conjunto a ser estudado de entidades e suas relações, trazendo o reconhecimento de que não temos apenas uma coleção de dados, mas uma série de atributos que os relacionam (Carley, 2002). Há várias medidas de rede, que podem ser classificadas em dois grupos, conforme a abordagem que se pretende: as medidas de grafo e as de atores. As medidas de grafo delineiam "quem" é a rede, selecionando indicadores que permitam traçar uma visão panorâmica de suas macrocaracterísticas. A abordagem focada nos atores utiliza-se de medidas que permitem a análise dos componentes e suas relações.

As medidas de grafo selecionadas foram: a distância média entre atores; a densidade da rede; o grau de fragmentação; a velocidade média de comunicação; as medidas de centralização. Foram identificados subgrupos na rede e os atores com maior potencial de fragmentá-la. As medidas para atores utilizam a centralidade de um ator como forma de avaliar seu poder na rede. 
Para adequação ao espaço disponível, este artigo apresenta apenas os cinco primeiros atores com maior pontuação para cada medida (Pinto, 2008).

\section{Resultados da pesquisa: análise da rede Cooperapic}

A análise da rede começa pela visão global da Cooperapic com o sociograma (figura 1), que representa a rede efetiva, apresentando as instituições-sede (agentes ou atores da rede), representadas pelos círculos e as unidades operacionais de cada instituição, representadas por quadrados. A figura permite identificar a forte concentração de laços ligados ao núcleo, que pode ser observado no círculo central. Também podem ser visualizadas as instituições com grande número de unidades de atendimento, mas com um débil relacionamento com as demais, o que é realçado nas elipses pontilhadas.

Figura 1

\section{Rede efetiva por agentes e unidades}

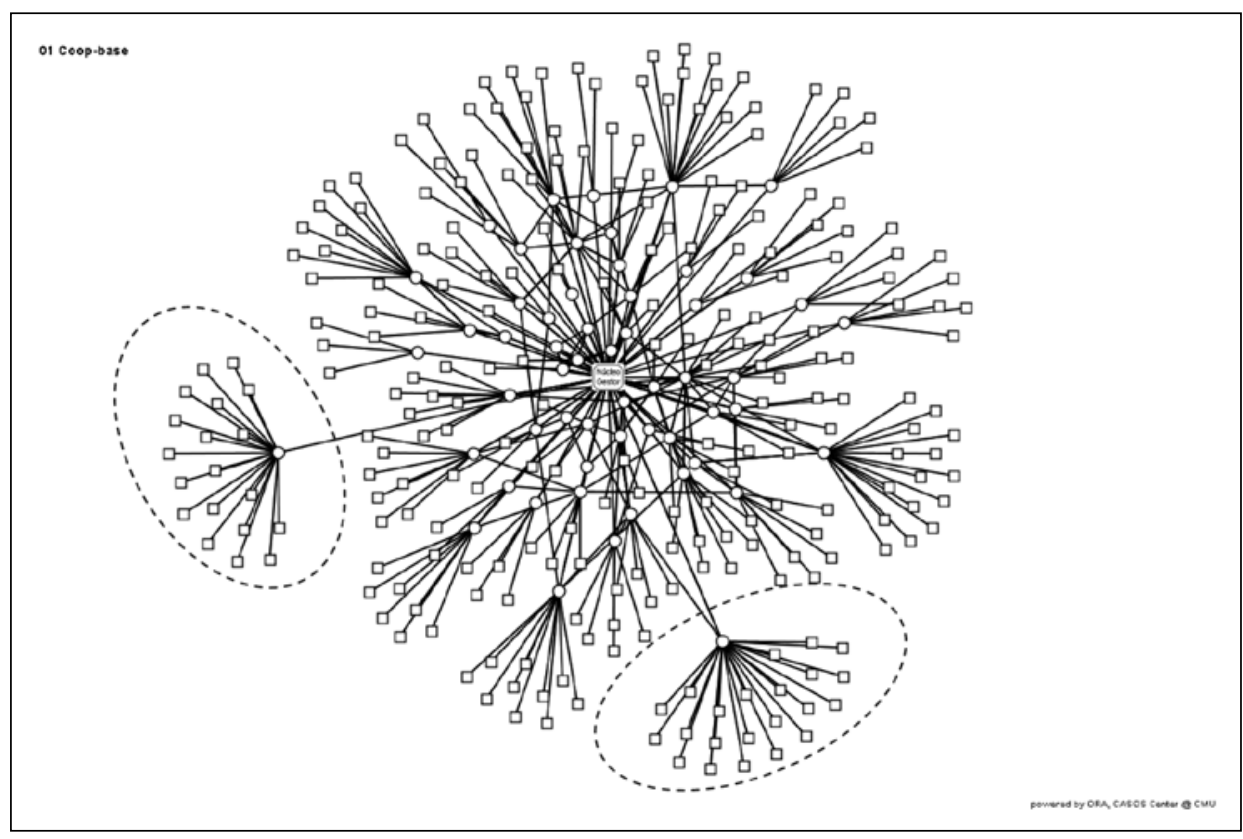

Selecionando somente os agentes e o relacionamento binomial, agente versus agente, pode-se identificar na rede efetiva (figura 2) que o núcleo gestor ocupa uma posição central. 
Figura 2

\section{Rede efetiva por agentes}

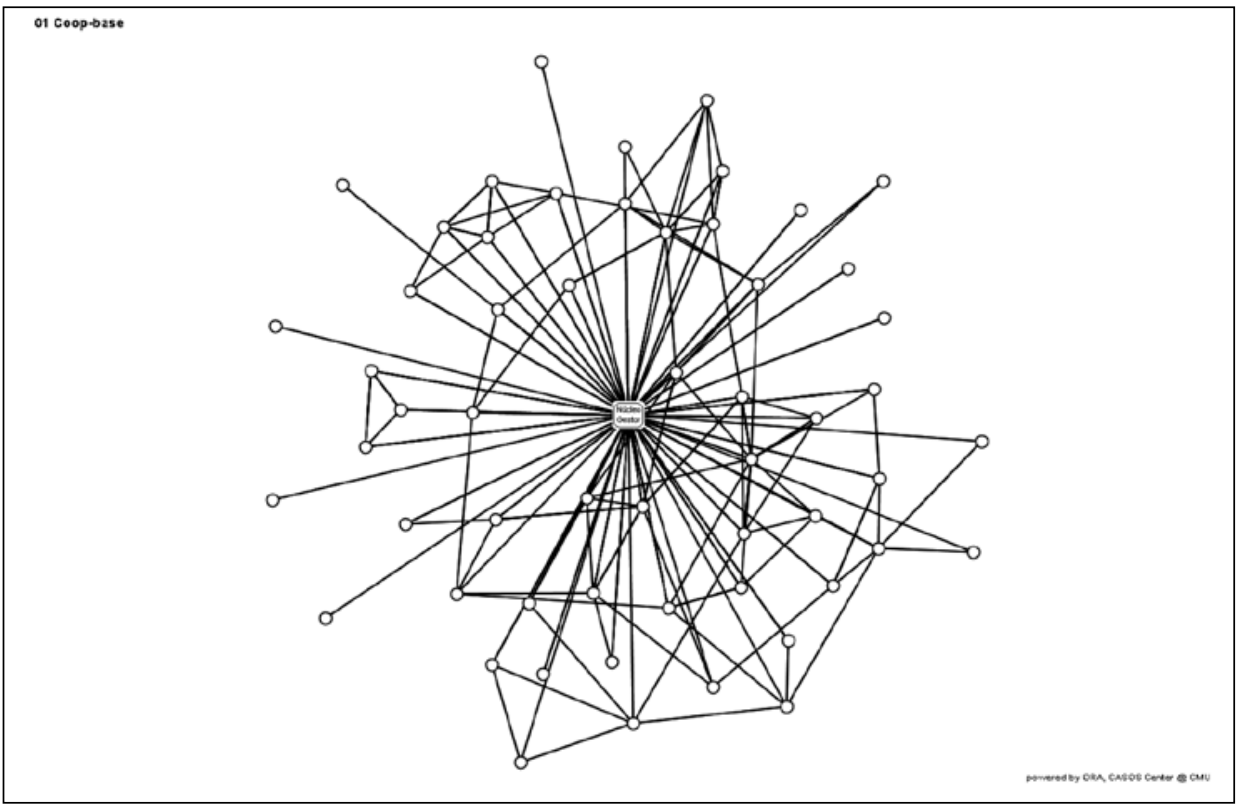

Distante da imagem idealizada de um grande grupo em que todos estão ligados a todos, a configuração real é assimétrica, com alguns agrupamentos bem conectados e outros subgrupos e atores dispersos ou fracamente vinculados.

Observando apenas os subgrupos de atores, foram usados artifícios para ampliar a visibilidade das relações (figura 3): excluiu-se do sociograma o núcleo gestor; indicou-se o sentido das conexões; foram redimensionados os círculos que representam os agentes, proporcionalmente ao número de unidades de atendimento; e, principalmente, foram identificados subgrupos de atores.

A criação de subgrupos de agentes pelo método de Newman e seu teste, por meio da modularidade proposta pelo autor (Newman e Girvan, 2004; Newman, 2006), mede o grau da estrutura comunitária no grupo. A Cooperapic teve um percentual de $63,7 \%$ de formação de grupos, o que indica uma estrutura modular definida. Foram encontrados seis agrupamentos distintos, ou comunidades, além dos atores dispersos, como é explicitado na figura 3.

Uma vinculação débil, calcada em contatos pouco frequentes com pares eventuais, ou apenas para suprir necessidades mais prementes ou pragmáticas, pode enfraquecer a rede. A rede sem núcleo (figura 3) também apresenta os atores desconectados, ou seja, aqueles que possuíam contato apenas com o núcleo, com sua retirada deixaram de ter vínculos com a rede. Muitos atores 
pouco conectados alegaram nas entrevistas que, mesmo não tendo deixado de pagar as mensalidades ou pedido exclusão no cadastro, tinham pouco ou nenhum contato com os demais associados. Dois atores afirmaram efetiva intenção de se desligar do grupo. Um deles declarou que não tinha contato e não percebia utilidade na continuidade do atuar em rede; outro afirmou só se manter em conexão pelo benefício do convênio médico, ao qual não teria acesso se não fosse com a rede.

Rede sem núcleo por número de unidades dos agentes

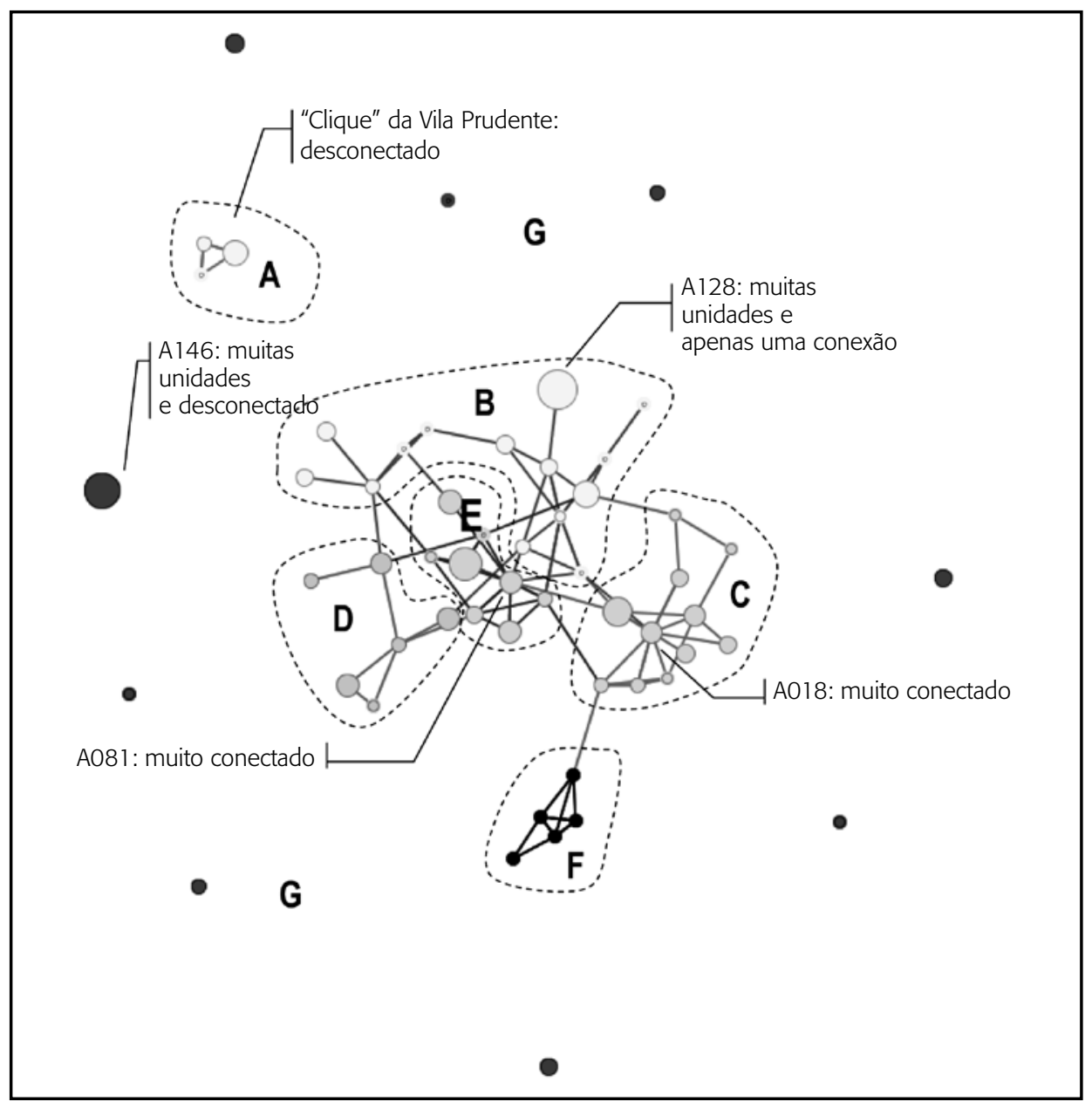

Legenda: A. Subgrupo de Vila Prudente. B. Subgrupo de M'Boi Mirim e Santo Amaro. C. Subgrupo de Capela do Socorro e Palhereiros. D. Subgrupo de Campo Limpo. E. Subgrupo Central. F. Subgrupo de Embu. G. Atores desconectados (os nós que mantinham conexão apenas com o núcleo gestor). 
A inspeção visual aponta alguns atores fortemente enredados na malha, como A081 e A018, e grupos fracamente conectados, como os atores na parte inferior central do grafo (subgrupo F), cujo contato é A131. Nota-se também um pequeno grupo (tríade) independente, no canto superior esquerdo do sociograma (subgrupo A), com forte conexão entre si, mas pouco ligado aos demais, que foi identificado como o subgrupo de Vila Prudente.

As declarações em entrevistas juntamente com esses primeiros sociogramas apontaram para uma ênfase nos agrupamentos - e consequentes relações de poder - tendo como base a localização. A maior parte das unidades $(82,3 \%)$ está em sete subprefeituras adjacentes, concentrando-se nas subprefeituras de Campo Limpo (subgrupo D), Capela do Socorro e M'Boi Mirim (subgrupos B e C), que congregam 1,5 milhão de habitantes, em bairros como Jardim Ângela e Capão Redondo, conhecidos pela alta taxa de criminalidade e deficiência de infraestrutura.

A proximidade física é importante fator de ligação nessa rede (tabela 1): os grupos de Capela do Socorro/Parelheiros e M’Boi Mirim/Santo Amaro são coesos entre si e declararam manter contatos frequentes; as entidades situadas em Campo Limpo intermedeiam e agregam contatos com diversos outros; o grupo de Embu está quase isolado; o clique de Vila Prudente (A138, A113 e A017), que soma 15 unidades de atendimento, estaria desconectado se não fosse sua ligação com a sede. Durante as entrevistas, os atores ligados a este último declararam um progressivo afastamento, motivado não por diferenças de objetivos, mas principalmente pela dificuldade de deslocamento para os encontros, que ocorriam invariavelmente na sede, na Zona Sul de São Paulo, região de difícil acesso para esses atores.

A conformação geográfica e o agrupamento pela modularidade de Newman apresentam resultados similares, comparando-se a tabela 1 e a figura 3 . Se cruzarem a localização com os serviços prestados, pode-se encontrar também três clusters na Cooperapic, com creches (CEIs e CCAs) localizadas nas subprefeituras de Campo Limpo, Capela do Socorro e M’Boi Mirim.

Tabela 1

Regiões de atuação e grupamentos de Newman

\begin{tabular}{|lcccccccc|}
\hline \multirow{2}{*}{ Região } & \multicolumn{9}{c}{ Grupamentos de Newman } & \multirow{2}{*}{ Total } \\
\cline { 2 - 7 } & A & B & C & D & E & F & G & \\
\hline Butantã & & & & & 1 & & & 1 \\
Campo Limpo & & 1 & & 4 & 1 & & 1 & 7 \\
Capela do Socorro & & & 8 & & 1 & & 1 & 10 \\
\hline
\end{tabular}




\begin{tabular}{|c|c|c|c|c|c|c|c|c|}
\hline \multirow{2}{*}{ Região } & \multicolumn{7}{|c|}{ Grupamentos de Newman } & \multirow{2}{*}{ Total } \\
\hline & A & B & $\mathrm{C}$ & D & $E$ & $\mathrm{~F}$ & G & \\
\hline Cidade Ademar & & 2 & & & 1 & & 2 & 5 \\
\hline Embu & & & & & & 5 & & 5 \\
\hline Jabaquara & & & & 1 & 1 & & & 2 \\
\hline Lapa & & & & & & & 1 & 1 \\
\hline M'Boi Mirim & & 7 & & & 1 & & & 8 \\
\hline Parelheiros & & 1 & 3 & & 1 & & & 5 \\
\hline Pinheiros & & & & & & & 1 & 1 \\
\hline Santo Amaro & & 3 & & 1 & 1 & & 1 & 6 \\
\hline Sé & & & & & & & 1 & 1 \\
\hline Vila Prudente & 3 & & & & 1 & & & 4 \\
\hline Total & 3 & 14 & 11 & 6 & 9 & 5 & 8 & 56 \\
\hline
\end{tabular}

A tendência aparente é que entidades que prestam os mesmos serviços na mesma região busquem apoio mútuo com maior intensidade, o que reforça uma das hipóteses iniciais. Os serviços oferecidos se concentram no extremo sul de São Paulo, um dos maiores bolsões de pobreza da cidade. Muitas organizações têm que lidar com carência de recursos, acesso precário, violência, tráfico e outros problemas típicos da periferia. Situar-se em uma mesma subprefeitura demanda também depender da relação com funcionários públicos comandados por cada subprefeito e por um grupo político dominante, o que talvez gere um contexto relacional similar com o poder público. Tais fatores podem proporcionar uma vinculação alicerçada em sentimentos de solidariedade e parceria, pela consciência de realizar um trabalho parecido, vivenciando uma realidade similar.

\section{Participação em projetos}

Excluindo-se a sede, 20 entidades (35,7\%) declararam não participar de nenhum dos projetos da Cooperapic. Outras 11 entidades (19,6\%) afirmaram participar apenas de projetos colaborativos, de formação ou apoio à gestão. E nove $(16,1 \%)$ disseram que sua participação era basicamente dirigida a benefícios (plano de saúde, convênios com faculdades e doações) e 16 (28,6\%) buscavam tanto benefícios quanto colaboração. A figura 4 apresenta os nós como círculos dimensionados de acordo com o número total de projetos dos quais participam. 
Figura 4

Rede sem núcleo por agente e número de projetos

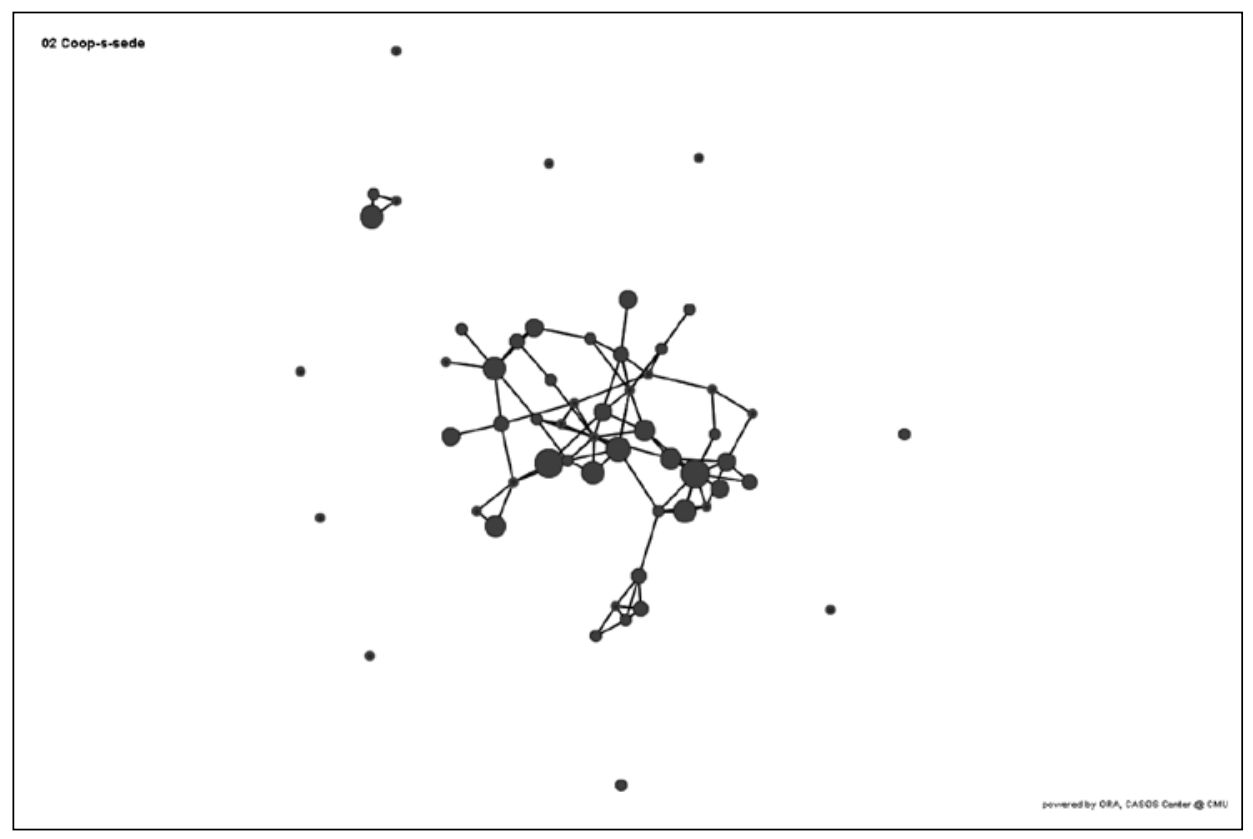

Pelo sociograma, muitos atores mais centrais e melhor relacionados também participam de muitos projetos, e os isolados tendem a ter pouca participação, com a exceção de A113, do grupo de Vila Prudente, que declarou participar de cinco projetos. Essa participação talvez justifique que o grupo se mantenha associado à rede, apesar da distância física. Nota-se aqui uma relação entre participação em projetos e poder dos atores, em que os mais participativos tenderiam a ser mais poderosos.

\section{Simulação de cenários: as medidas de grafo para a rede efetiva e a rede sem núcleo}

A avaliação dos sociogramas indicou que a localização, o tipo de serviço prestado e a participação em projetos são fatores importantes de relacionamento (e, por conseguinte, de poder) dos atores. As medidas de grafo tornam as observações mais assertivas, à medida que permitem medir de forma padronizada a rede. Ao se comparar a rede efetiva e a rede sem núcleo (figura 2 e figura 3), usando-se os sociogramas, nota-se que o número de 
ligações efetivas é significativamente menor ao retirar-se o núcleo gestor. A quantificação demonstra uma queda de 122 para 83 arestas — uma redução de $32 \%$ entre o primeiro e o último cenário, o que indica o poder relacional do núcleo.

A análise de medidas de grafos se baseou na comparação entre os indicadores de redes para os dados de cada cenário. A tabela 2 apresenta mensurações selecionadas, em uma visão macro. Cada uma das medidas será interpretada.

Tabela 2

Medidas de grafo da rede nos cenários

\begin{tabular}{|lcc|}
\hline Medidas de grafo & Rede efetiva & Rede sem núcleo \\
\hline Distância média & 2,02 & 4,17 \\
Densidade & 0,06 & 0,03 \\
Fragmentação & - & 0,38 \\
Velocidade média de comunicação & 0,50 & 0,24 \\
Centralização - intermediação & 0,76 & 0,11 \\
Centralização - proximidade & 1,19 & 0,02 \\
Centralização - grau de entrada & 2,92 & 0,56 \\
Centralização - grau de saída & 3,86 & 0,28 \\
\hline
\end{tabular}

Na rede efetiva, um ator está a uma distância média de dois atores para acessar outro ator; sem a sede, a distância duplica: a presença da sede encurta as distâncias entre atores e melhora a comunicação total. A medida de densidade indica que, se há baixo acoplamento entre atores, a quantidade total de poder na rede também é baixa, pois há poucos contatos entre os atores para que ele possa ser exercido. A Cooperapic, em qualquer dos cenários, tem relações muito pouco densas, atingindo um percentual máximo de $6 \%$ do total de ligações possíveis na rede efetiva, indicando que a maioria dos associados não estabeleceu vínculos fortes. A rede sem núcleo tem uma densidade de apenas $3 \%$.

A rede efetiva não é fragmentada, por definição. Ao se excluir o núcleo gestor, revela-se que $38 \%$ dos atores ficariam desconectados e sem pontos de contato com os demais. 
A medida de velocidade média de comunicação apresenta um menor comprimento de caminho médio entre atores, respectivamente, de 0,50 e 0,24 para as redes efetiva e sem núcleo. A manutenção de uma comunicação ágil reduz-se sensivelmente com a retirada do núcleo, duplicando-se o tempo para uma mensagem se mover pela rede, o que indica a importância dele na eficiência da rede.

As medidas de centralização de Freeman (1979) comparam a rede Cooperapic em relação a uma rede estrela perfeita (uma rede em que todos se ligam a todos) de mesmo tamanho. Essas medidas indicam uma concentração de poder muito maior no cenário da rede efetiva do que na rede sem núcleo, motivada tanto pelo grande número de relacionamentos do núcleo, quanto pelo vínculo próximo existente entre atores que têm poucos contatos adicionais e o núcleo, o que dá poder a este último: sua posição privilegiada reforça a capacidade do núcleo agir como intermediário, não só pela sua ligação com outros atores poderosos, mas também porque muitos dependem dele para acessar outros atores na rede.

\section{Centralidade do poder na Cooperapic}

A seguir, apresenta-se a interpretação das medidas para os atores, nos dois cenários da Cooperapic. Essa etapa se iniciou com a identificação dos agentes que estão pontuados entre os três principais em cada uma das medidas de centralidade e poder, para avaliar sítios com risco de desagregação das relações. A rede efetiva apresenta apenas um ator (A000 - o próprio núcleo gestor) que, se removido da rede, cria novos componentes. A análise da Cooperapic sem esse ator, identifica oito atores "porteiros" ou boundary spanners ( $14 \%$ dos atores) com alta intermediação e baixa centralidade, e que podem criar pontos de cisão na rede, resultando em grupos não conectados. O poder desses atores advém justamente da sua capacidade de provocar rupturas. A figura 5 destaca os boundary spanners no sociograma por círculos de maior dimensão.

Se por um lado esses atores têm o importante papel de promover a ligação com atores menos conectados, por outro, nota-se que eles têm uma baixa participação nas atividades reticulares, e a medida de baixa centralidade confirma-se no limitado uso que eles fazem das possibilidades e projetos oferecidos pela rede. As informações adicionais obtidas nas entrevistas confirmaram a possibilidade de saída desses atores. 
Figura 5

Rede sem núcleo: boundary spanners

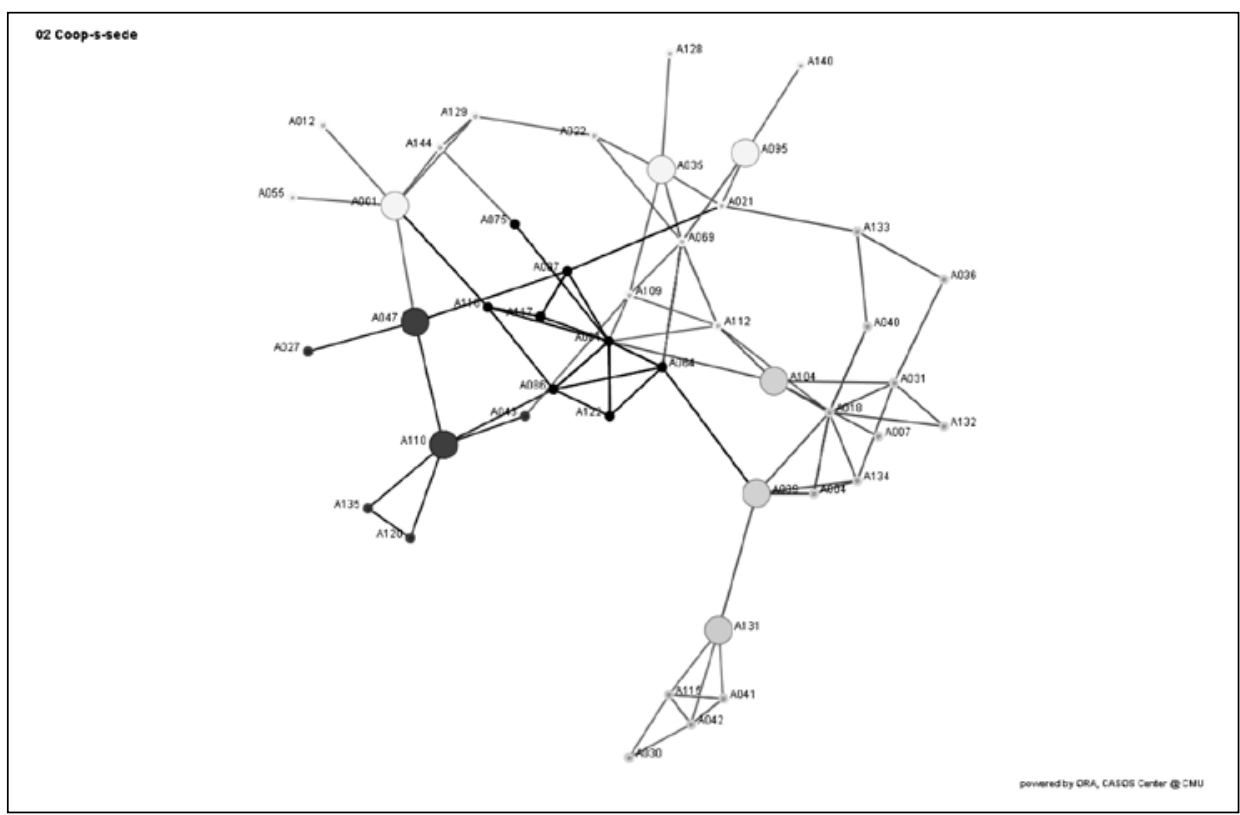

Os cinco agentes com maior centralidade de intermediação, mas baixo grau de centralidade total (boundary spanner potential) foram listados na tabela 3. Eles agem, potencialmente, como ligação entre grupos de entidades, e sua remoção também pode fragmentar a Cooperapic.

Tabela 3

Boundary spanner potential

\begin{tabular}{|llll|}
\hline \multicolumn{2}{|c}{ Rede efetiva } & \multicolumn{2}{c|}{ Rede sem núcleo } \\
\hline A000 & 0,31 & A104 & 0,15 \\
A110 & 0,15 & A086 & 0,07 \\
A043 & 0,14 & A112 & 0,07 \\
A086 & 0,11 & A001 & 0,07 \\
A129 & 0,05 & A116 & 0,06 \\
\hline
\end{tabular}

A centralidade de intermediação média (tabela 4) da Cooperapic é baixa e idêntica $(0,02)$ nos dois cenários. A sede tem uma medida $(0,76)$ muito superior a todos os outros atores, agindo como o principal concentrador de 
poder via intermediação da rede. A exclusão da sede evidenciaria os atores A081 e A018 com os mais elevados índices de centralidade de intermediação, tornando-se os principais brokers de relações indiretas por meio da rede, podendo negociar ou prevenir contatos entre os demais.

Tabela 4

Centralidade de intermediação

\begin{tabular}{|cccc|}
\hline \multicolumn{2}{|c}{ Rede efetiva } & \multicolumn{2}{c|}{ Rede sem núcleo } \\
\hline A000 & 0,76 & A081 & 0,13 \\
A086 & 0,02 & A018 & 0,12 \\
A110 & 0,02 & A064 & 0,10 \\
A043 & 0,02 & A086 & 0,09 \\
A069 & 0,01 & A069 & 0,08 \\
\hline
\end{tabular}

A partir do conceito que um ator pode obter poder ao se manter conectado a muitos outros com poucas conexões - alpha centrality ou centralidade de poder de Bonacich (Bonacich, 1987; Wasserman e Faust, 1999) — a sede obtém (tabela 5 e figura 6), no cenário "efetiva", uma pontuação de 225 , muito além do segundo colocado (A117) com 28 , conforme se vê na tabela 5 , que apresenta os 10 atores que têm maior centralidade de poder pelo indicador desenvolvido por Bonacich. Os atores conectados apenas ao núcleo gestor teriam forte dependência dele, que, por sua vez, concentraria grande poder na rede. Se a sede for excluída, os quatro agentes com maior pontuação ainda permanecem como os quatro melhores colocados, mas o agente A031 cai para a $6^{\mathrm{a}}$ colocação e o agente A022, que ocupava a $10^{\mathrm{a}}$ posição no cenário rede efetiva, passa para $5^{\circ}$ colocado. A117 e A064, $2^{\circ}$ e $3^{\circ}$ colocados, continuam bem pontuados, mas seu poder se reduz em valores absolutos, o que indica que a presença da sede também lhes ampliava o poder. Vale notar a ligação entre três atores poderosos - A117, A064 e A081 - no subgrupo E, pelo critério de Newman, e dos atores A022, A035 e A069 no subgrupo B.

Tabela 5

Centralidade de poder segundo Bonacich

\begin{tabular}{|rrrr|}
\hline \multicolumn{2}{|c}{ Rede efetiva } & \multicolumn{2}{c|}{ Rede sem núcleo } \\
\hline A000 & 225,00 & $\mathrm{~A} 117$ & 21,00 \\
A117 & 28,00 & $\mathrm{~A} 064$ & 20,00 \\
A064 & 24,00 & $\mathrm{~A} 081$ & 18,00 \\
A081 & 24,00 & $\mathrm{~A} 035$ & 15,00 \\
A031 & 21,00 & $\mathrm{~A} 022$ & 15,00 \\
\hline
\end{tabular}


Figura 6

\section{Centralidade do poder segundo Bonacich}

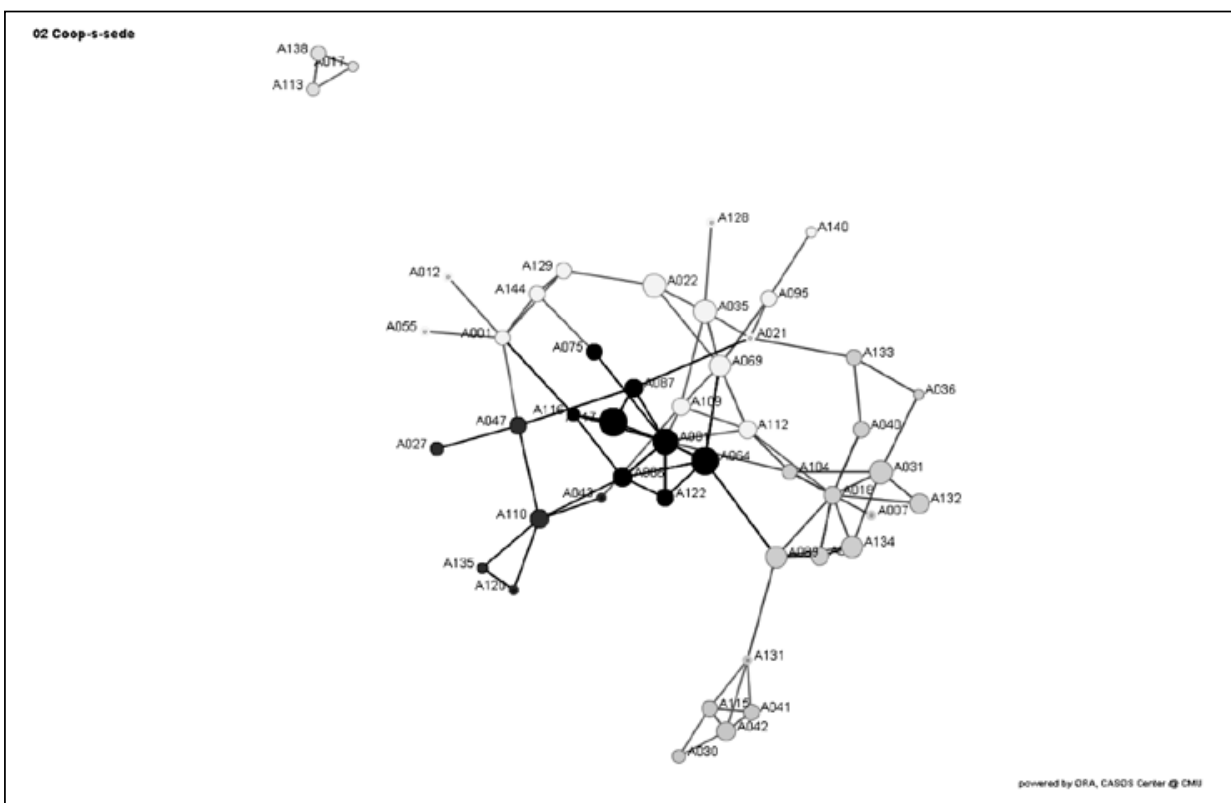

A centralidade de proximidade (caminho médio de uma pessoa a outra na rede - tabela 6) indica que no cenário rede efetiva o ator A000, o núcleo gestor, tem vital responsabilidade na coleta e distribuição de informações na rede, mas 42 outros atores têm importante contribuição e medida superior a 0,50. E 10 atores (17\%) pontuam no mínimo de 0,02.

O modelo rede sem núcleo demonstra um baixo escore, com pouca dispersão, para todos os atores (entre 0,04 e 0,02) indicando um maior distanciamento deles. E 17 atores (30\%) tiveram a pontuação mínima de 0,02.

\section{Tabela 6}

Centralidade de proximidade

\begin{tabular}{|llll|}
\hline \multicolumn{2}{|c|}{ Rede efetiva } & \multicolumn{2}{c|}{ Rede sem núcleo } \\
\hline A000 & 1,00 & A022 & 0,04 \\
A064 & 0,53 & A 144 & 0,04 \\
A087 & 0,52 & A 129 & 0,04 \\
A112 & 0,52 & A087 & 0,04 \\
A069 & 0,52 & A117 & 0,04 \\
\hline
\end{tabular}


A centralidade de autovetor (centrality eigenvector) supõe que uma rápida difusão de informações pode ser propiciada pela ligação de um agente muito conectado com outros também muito conectados. A Cooperapic apresenta um escore geral muito baixo (tabela 7), em todos os modelos, com média de 0,02 e desvio-padrão de 0,02 (rede efetiva) a 0,03 (rede sem núcleo). Nessa medida, 12 atores (21\%) tiveram pontuação zero, no modelo rede sem núcleo. Essa comunicação pouco eficiente foi constatada também durante as entrevistas, pois não havia, na Cooperapic, um mecanismo de informes simples e funcional. A carência de ferramental tecnológico por parte dos atores - computadores e acesso à internet - pode ser uma das causas para isso, mas esse diagnóstico não fez parte do escopo da pesquisa.

O melhor escore individual, mesmo que ainda baixo, na rede efetiva é o da sede $(0,11)$, com o dobro do segundo colocado (A128 - 0,05). Na rede sem núcleo sobressaem-se os agentes A018, com 0,13 e A031, com uma medida de 0,11.

Tabela 7

\section{Centralidade de autovetor}

\begin{tabular}{|cccc|}
\hline \multicolumn{2}{|c|}{ Rede efetiva } & \multicolumn{2}{c|}{ Rede sem núcleo } \\
\hline A000 & 0,11 & A018 & 0,13 \\
A128 & 0,05 & A031 & 0,11 \\
A018 & 0,04 & A081 & 0,07 \\
A081 & 0,04 & $A 132$ & 0,06 \\
A031 & 0,04 & A089 & 0,05 \\
\hline
\end{tabular}

Na centralidade de grau de entrada (tabela 8) a sede é o ator de maior prestígio, ou seja, o mais citado por outros, pois tem um placar de 3,09 (173 referências diretas e indiretas) na simulação base. O prestígio, por si só, não pode impor comportamentos, mas uma alta visibilidade pode influenciar por meio da indução de um comportamento imitativo. A081 e A018 também se destacam pelo grande volume de indicações de laços por outros atores (tabela 8).

Tabela 8

Centralidade de grau de entrada

\begin{tabular}{|cccc|}
\hline \multicolumn{2}{|c}{ Rede efetiva } & \multicolumn{2}{c|}{ Rede sem núcleo } \\
\hline A000 & 3,09 & A081 & 0,65 \\
A081 & 0,75 & $A 018$ & 0,64 \\
A018 & 0,73 & A069 & 0,40 \\
A069 & 0,45 & A086 & 0,24 \\
A128 & 0,39 & A122 & 0,24 \\
\hline
\end{tabular}


A sede também tem poder de influenciar diretamente outros (maior centralidade de grau de saída - tabela 9), com 225 referências no modelo rede efetiva (medida de 4,02). A117 se destaca com uma medida de 0,50 para a rede efetiva e 0,38 para a rede sem núcleo. Diversos atores mais centrais também participam de muitos projetos e os isolados tendem a ter pouca participação, com a exceção de A113, do grupo de Vila Prudente, que declarou participar de cinco projetos. Tal participação talvez justifique que esse grupo se mantenha associado à rede, apesar da distância física. A seguir, em ambos os modelos, estão os mesmos atores: A064 e A081. Se as relações excluíssem A000, A081 ganharia influência $(0,84)$ e A064 perderia $(0,46)$.

Tabela 9

Centralidade de grau de saída

\begin{tabular}{|cccc|}
\hline \multicolumn{2}{|c}{ Rede efetiva } & \multicolumn{2}{c|}{ Rede sem núcleo } \\
\hline A000 & 4,02 & A117 & 0,38 \\
A117 & 0,50 & A064 & 0,36 \\
A064 & 0,43 & A081 & 0,33 \\
A081 & 0,43 & A035 & 0,27 \\
A031 & 0,38 & A022 & 0,27 \\
\hline
\end{tabular}

Resumindo as evidências apontadas nos sociogramas e medidas, o poder se concentra no núcleo gestor e em seis e 10 atores adicionais. A maioria deles foi identificada pelo núcleo (sem que este tivesse conhecimento dos resultados da pesquisa) como membros ativos, participativos e atuantes, com contatos constantes com a organização central e outros atores. Os atores A081 e A018 demonstram o maior potencial de intermediação, se a sede fosse excluída. A centralidade de poder de Bonacich também indica forte concentração na sede e nos atores A117, A064 e A081.

Já a percepção da existência de boundary spanners não foi tão evidente aos gestores: há oito atores com baixa centralidade e que atuam como ligações entre grupos, cuja remoção ou saída pode cindir a rede, e não foram identificados pelo núcleo, possivelmente porque eles revelaram nas entrevistas uma fraca participação nos projetos cooperativos, confirmando o apontamento das medidas.

A estrutura e os laços entre atores condicionaram as relações de poder na rede pesquisada. Além disso, observou-se que atores com fácil acesso entre si apresentaram tendência a se comunicar mais e reforçar relações, formando 
subgrupos. Esse melhor acesso foi propiciado pela proximidade geográfica entre eles, pela participação conjunta em projetos e pela prestação de serviços similares. A atuação em uma mesma região foi o fator decisivo para a promoção da união entre os agentes: subgrupos se formaram principalmente em função de os atores se localizarem próximos.

Se por um lado os atores situados na mesma subprefeitura ou bairro, operando com serviços similares, tenderam a se aglutinar em clusters relativamente independentes, por outro, a participação de atores nos mesmos projetos da rede Cooperapic também se mostrou relevante. Enquanto os dois primeiros fatores - localização e similaridade de serviços - alicerçaram a solidariedade local, o último - participação em projetos - reforçou a integração de todos os participantes, à medida que propiciou trocas entre os grupos e os atores de distintas regiões.

O esforço de manutenção de laços solidários teve recompensa, pois atores mais participativos tenderam também a ser os mais poderosos. Esse poder adveio da intermediação de contatos, da posição favorável para triar informações, da proximidade com o núcleo gestor e também da unilateralidade de muitas citações.

Como os relacionamentos, em geral, não são intensos, e nenhum dos tipos de vínculos apontados foi de natureza crucial para a existência dos atores, a perda dos vínculos poderia, na maior parte dos casos, causar apenas consequências menores aos atores.

\section{Considerações finais}

As relações entre os subgrupos da Cooperapic são mais intensas do que na rede como um todo, havendo um equilíbrio entre interesses coletivos e individuais. As medidas de grafos e de atores indicaram que a rede Cooperapic é descentralizada, pouco densa de relacionamentos e com comunicação pouco eficiente, predominando relações assimétricas e frágeis entre os atores, com baixa centralidade de intermediação e mesmo de informação.

As medidas não indicaram que a rede disponha de capacidade de mobilização, possivelmente porque foram extraídas num contexto pouco turbulento e sem grandes desafios externos, o que talvez não ocorra em uma situação de crise que afete de forma solidária os atores. Como as organizações da rede já possuem elos estabelecidos, isso pode contribuir para reforçar a união e articular uma mobilização rápida e incisiva, multiplicando as vin- 
culações e o poder de pressão da rede, fazendo valer os interesses dos seus integrantes.

Do ponto de vista interno, a Cooperapic é uma rede horizontal, em que os participantes possuem autonomia, que se exerce por meio de mecanismos democráticos, como assembleias mensais e votações, e o poder é distribuído de maneira similar para a maioria dos atores. Entretanto, há uma distribuição assimétrica do poder dentro da Cooperapic, porque a posição do núcleo gestor da rede permite que este concentre mais poder do que qualquer outro membro.

O poder que ele exerce deve-se em grande parte à sua articulação na rede, mais do que fora dela. O núcleo gestor facilita não apenas comunicações como intermedeia contatos, promove relacionamentos, incentiva e oferece recursos, bem como espaços de convívio entre os seus membros. Ele é influente e tem prestígio na Cooperapic, ocupando posição de destaque quando se considera a centralidade do poder, pois é um ator do qual dependem outros atores.

A ação integradora e a posição central do núcleo gestor contribuem fortemente para a manutenção da rede e seu crescimento. Contudo, a simulação revelou que, apesar de detentor de poder na rede, este núcleo não é essencial, ou seja, sua ausência não provoca fragmentação tal que desintegre a rede. A simulação de exclusão do núcleo gestor apontou que o vácuo deixado por ele abriria brechas para que alguns membros se desligassem da rede, individualmente ou em pequenos grupos. Isso significaria perdas relativamente baixas, ocorrendo principalmente entre atores que mantêm pouco ou nenhum contato com os demais membros da rede. São mais atores isolados do que membros efetivamente atuantes na rede.

Assim, o interesse colaborativo poderia superar o custo de continuar associado, pois a maioria dos atores está entrosada para a manutenção da rede, mediante os vínculos gerados pelos projetos, ação regional e prestação de serviços. Alguns desses atores despontam como lideranças conscientes na manutenção da rede, evidenciada pela maior centralidade na sua gestão.

A pesquisa foi unimodal, privilegiando o curto prazo e as relações imediatas, analisadas de forma binária (presença/ausência de vínculos). Diferentes análises, multimodais, poderão abordar facetas adicionais dos dados levantados na pesquisa. Outras pesquisas poderão ser realizadas, buscando entender as energias que venham a determinar a dissolução das redes, bem como o histórico das relações individuais entre atores, que explicitem dimensões adicionais da rede, enriquecendo a análise de grafos. 


\section{Referências}

ACIOLI, S. Redes sociais e teoria social: revendo os fundamentos do conceito. Revista Informação e Informação, Londrina, v. 12, n. 0, 2007. Disponível em: <www. uel.br/revistas/uel/index.php/infoteste/article/view/1313>. Acesso em: 10 jan. 2008.

ARENDT, H. A condição humana. Rio de Janeiro: Forense Universitária, 2000.

. O que é política? 5. ed. Rio de Janeiro: Bertrand Brasil, 2004.

BONACICH, P. Power and centrality: a family of measures. American Journal of Sociology, v. 92, n. 5, p. 1170-1182, Mar. 1987.

BURT, R. S. Structural hole. Cambridge, MA: Harvard University Press, 1992.

CARLEY, K. M. Smart agents and organizations of the future - the handbook of new media. Thousand Oaks, CA: Sage, 2002.

. Dynamic network analysis in dynamic social network modeling and analysis: workshop summary and papers. In: BREIGER, Ronald; CARLEY, Kathleen; PATTISON, Philippa (Eds.). Committee on human factors, national research council. Washington, DC, 2003.

. ORA: version 1.9.5.2.6. Center for Computational Analysis of Social and Organizational Systems. Pittsburgh: Carnegie Mellon University, 2008.

; REMINGA, J. ORA: organization risk analyzer. Casos technical report. Carnegie Mellon University, School of Computer Science. Jan. 2004. Disponível em: <www.casos.ece.cmu.edu>. Acesso em: 1 mar. 2008.

ELIAS, Norbert. A sociedade dos indivíduos. Rio de Janeiro: Jorge Zahar, 1994.

FLEURY, S.; MIGUELETTO, D.; BLOCH, R. Gestão de uma rede solidária: o caso do Comitê das Entidade Públicas no Combate à Fome e pela Vida. Cadernos da Oficina Social, p. 249-275, 2002.

; OUVERNEY, A. M. Gestão de redes: a estratégia de regionalização da política de saúde. Rio de Janeiro: FGV, 2007.

FOUCAULT, M. Microfísica do poder. 3. ed. Rio de Janeiro: Graal, 1982.

FREEMAN, L. C. Centrality in social networks I: conceptual clarification. Social Networks, n. 1, p. 215-239, 1979.

GRANOVETTER; M. The strength of weak ties. American Journal of Sociology, p. 78, 1973.

. Economic action and social structure: the problem of embeddedness. American Journal of Sociology, v. 91, n. 3, p. 481-510, 1985. 
HANNEMAN, R. A.; RIDDLE, M. Introduction to social network methods. Riverside, CA: University of California, 2005. Disponível em: <http://faculty.ucr.edu/ hanneman/>. Acesso em: 2 out. 2007.

JUNQUEIRA, L. A. P. Conselhos municipais e a gestão de rede das políticas sociais. Informativo Cepam, São Paulo, v. 1, p. 26-31, 2002.

. Organizações sem fins lucrativos e redes sociais na gestão das políticas sociais. In: CAVALCANTI, M. (Org.). Gestão social, estratégias e parcerias: redescobrindo a essência da administração para o terceiro setor. São Paulo: Saraiva, 2006. v. 1, p. $195-218$.

MARQUES, E. C. Redes sociais, instituições e atores políticos no governo da cidade de São Paulo. São Paulo: Annablume/Fapesp, 2003.

MARTELETO, R. M. Análise e redes sociais: aplicação nos estudos de transferência da informação. Ciência da Informação, Brasília, v. 30, n. 1, p. 71-81, jan./abr. 2001.

; SILVA, A. B. O. Redes e capital social: o enfoque da informação para o desenvolvimento local. Ciência da Informação, Brasília, v. 33, n. 3, p. 41-49, set./ dez. 2004.

MARTES, A. C. B. et al. Fórum - redes sociais e interorganizacionais. Revista de Administração de Empresas, v. 46, n. 3, p. 10-15, 2006.

MIZRUCHI, M. What do interlocks do? An analysis, critique, and assessment of research on interlocking directorates. Annual Review of Sociology, v. 22, p. 271298, 1996.

. Análise de redes sociais: avanços recentes e controvérsias atuais. Revista de Administração de Empresas, v. 46, n. 3, p. 72- 86, 2006.

NEWMAN, M. E. J. Modularity and community structure in networks. PNAS, v. 103, n. 23, p. 8577-8582, June 2006. Disponível em: <www.pnas.org/ content/103/23/8577>. Acesso em: 14 jun. 2008.

; GIRVAN, M. Finding and evaluating community structure in networks. Physical Review E (Statistical, Nonlinear, and Soft Matter Physics), v. 69, n. 2, 2004.

NOHRIA, N.; ECCLES, R. G. (Orgs.). Network and organizations: structure, form and action. Boston: Harvard Business School Press, 1992.

NONAKA, I.; TAKEUCHI, H. The knowledge-creating company: how Japanese companies create the dynamics of innovation. New York: Oxford University Press, 1995. 
PINTO, A. M. G. As relações de poder em redes do terceiro setor. 2008. Dissertação (Mestrado em Administração) — Pontifícia Universidade Católica de São Paulo.

UZZI, B. The sources and consequences of embededdness for the economic performance of organizations: the network effect. American Sociological Review, v. 61, p. 674-698, 1996.

VILLASANTE, T. R. Redes e alternativas: estratégias e estilos criativos na complexidade social. Rio de Janeiro: Vozes, 2002.

WASSERMAN, S.; FAUST, K. Social network analysis: methods and applications. Cambridge, UK: Cambridge University Press, 1999. 